\title{
Luminescence resonance energy transfer-based intramolecular distance measurements in leucine transporter from Aquifex aeolicus
}

\author{
Azmat Sohail ${ }^{1}$, Peggy Stolt-Bergner ${ }^{2}$, Gerhard F Ecker ${ }^{3}$, Michael Freissmuth ${ }^{1}$, Harald Sitte ${ }^{1 *}$, Walter Sandtner ${ }^{1}$ \\ From 16th Scientific Symposium of the Austrian Pharmacological Society (APHAR) \\ Vienna, Austria. 25-27 November 2010
}

\section{Background}

Solute carrier 6 (SLC6) membrane proteins are integral membrane proteins and of particular pharmacological interest because they are targets of many clinically important drugs. These SLC6 proteins play crucial roles ranging from nutrient uptake to neurotransmitter clearance. A leucine transporter LeuT $\mathrm{T}_{\mathrm{Aa}}$ from Aquifex aeolicus has been recognized as a bacterial orthologue of mammalian SLC6 family proteins. Leu $\mathrm{T}_{\mathrm{Aa}}$ has been crystallized and its structure was resolved to high resolution. With respect to its kinship to other SLC6 transporters, though with low sequence identity ( 20-25\%), there are crucial regions in transmembrane segments 1 , 3,6 and 8 where conservation reaches $\sim 50 \%$. For this very reason LeuT $_{\mathrm{Aa}}$ provides a good structural paradigm to study homology models of SLC6 family members and learn more about the structure/function relationship in mammalian transporters.

\section{Methods and results}

In order to test proposed models, we initiated a study to measure intramolecular distance changes associated with the dynamic process of substrate transport. We employed luminescence resonance energy transfer (LRET) to measure the changes in intramolecular distances. For LRET-based measurements we have introduced LBT (lanthanide binding tags) to accommodate terbium, as the donor element, along with cysteines, where acceptor fluorophores are attached, at selected positions in Leu$\mathrm{T}_{\mathrm{Aa}}$. After expression and purification of these mutants, we obtained the first distances at atomic resolution.

\footnotetext{
* Correspondence: harald.sitte@meduniwien.ac.at

${ }^{1}$ Institute of Pharmacology, Center of Physiology and Pharmacology, Medical University of Vienna, 1090 Vienna, Austria
}

Full list of author information is available at the end of the article

\section{Conclusions}

Taken together our LRET measurements can help us to validate or propose a dynamic substrate transport model for LeuT $\mathrm{T}_{\mathrm{Aa}}$. Our future plan focusses on the establishment of functionality assays for screening of functional LeuT $_{\mathrm{Aa}}$ mutants along with their LRET measurements.

\section{Author details}

'Institute of Pharmacology, Center of Physiology and Pharmacology, Medical University of Vienna, 1090 Vienna, Austria. ${ }^{2}$ Research Institute of Molecular Pathology, Campus Vienna Biocenter, 1030 Vienna, Austria. ${ }^{3}$ Department of Medicinal Chemistry, University of Vienna, 1090 Vienna, Austria.

Published: 16 November 2010

\section{doi:10.1186/1471-2210-10-S1-A31}

Cite this article as: Sohail et al:: Luminescence resonance energy transfer-based intramolecular distance measurements in leucine transporter from Aquifex aeolicus. BMC Pharmacology 2010 10(Suppl 1): A31.

Submit your next manuscript to BioMed Central and take full advantage of:

- Convenient online submission

- Thorough peer review

- No space constraints or color figure charges

- Immediate publication on acceptance

- Inclusion in PubMed, CAS, Scopus and Google Scholar

- Research which is freely available for redistribution 